\title{
A FUZZY LOGIC APPROACH TO NON-LINEARITY PROBLEM OF LOAD FREQUENCY CONTROLLER
}

\author{
S. 0 Okozi ${ }^{1}{ }^{*}$, V. C. Madueme ${ }^{2}$ and M. A. Ndubisi ${ }^{3}$

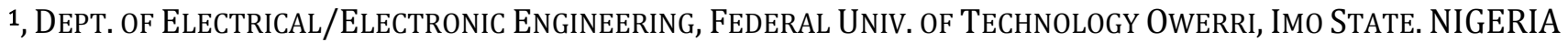 \\ 2 DEPARTMENT OF ELECTRICAL ENGINEERING, UNIVERSITY OF NigERIA NSUKKA, ENUGU STATE. NIGERIA \\ 3 EnUgu Electricity Distribution Company, OKPARA AVEnUe, EnUgu. EnUgu STATE. NiGERIA. \\ E-mail addresses:1 samokozy@yahoo.com,2 victory.madueme@unn.edu.ng,3ahusam99@yahoo.com
}

\begin{abstract}
In power systems, both active and reactive power demands are never steady. Due to sudden load changes, frequency fluctuation problems occur in an interconnected power system. The Load Frequency Control (LFC) reduces the frequency deviation and maintains dynamic performance of the system. Non-linearities have made most of the controllers employed for the LFC inefficient. In this paper, a fuzzy logic proportional integral (PI) controller is proposed to eliminate these setbacks with the conventional controllers. The results showed a reduction in settling time, percent overshoot and steady state error.
\end{abstract}

Keywords: fuzzy logic control, Area control error (ACE), power system control, load frequency control, Artificial intelligence.

\section{INTRODUCTION}

Power system is an interconnection of generating units to load centers through high voltage grid lines. In Power systems, natural energy is converted into electric power. The major sources of energy supplied by utility companies are either the kinetic energy from water or thermal energy from fossil fuels, or nuclear fission [1]. These energies are converted into mechanical energy by prime movers. The mechanical energy is in turn changed into electrical energy with the help of synchronous generators. To optimize the performance of electrical equipment, it is important to ensure the quality of the electric power. A good quality of the electric power system requires both the frequency and voltage to remain at standard values during operation.

In power system, the main objectives of the control strategy is to generate and deliver power as economically and reliably as possible in an interconnected system while maintaining the voltage and frequency in the steady-state within permissible limits [2]. An electric power system that is well designed and operated must cope with changes in the load and with system disturbances, and it should provide acceptable high level of power quality while maintaining both voltage and frequency within acceptable limits. This, thus, brought about the concept of power system control.

Power system control refers to the application of control theory and technology, optimization methodologies, and expert and intelligent systems to improve the performance and functions of power systems during stable and unstable conditions. Power system controls keep the power system in a state of stability and protect it from unstable phenomena. Power system stability is the ability of an electric power system to regain a state of operating equilibrium given an initial operating condition after being subjected to a physical disturbance, with most system variables bounded so that practically the entire system remains intact.

From the control point of view, these controls are either continuous or discontinuous. The set of continuous controls include generator excitation, prime mover and load frequency controls. The continuous control nature of both frequency and voltage make these parameters very important controls in power systems. 
The stable operation of frequency and voltage is therefore a very important factor in determining the quality of power supply, hence the flow of active and reactive power is vital to the satisfactory performance of power systems. The variation of frequency of a power system depends basically on the active (real) power balance while changes in reactive power affect the magnitude of the voltage [3].

The excitation time constant is much smaller than the prime mover time constant, its transient decays much faster. For this reason, the cross-coupling between the frequency loop and voltage loop is negligible, and hence the load frequency and excitation voltage control can be analyzed independently.

Load Frequency Control (LFC) is a very important issue in power system operation and control for supplying sufficient and reliable electric power with good quality. The major task of the Load Frequency Control (LFC) is to keep the frequency constant against the randomly varying active power loads, which are also referred to as external disturbance. As [4] puts it, the main goal of the LFC is to maintain zero steady state errors for frequency deviation and good tracking load demands in a multi-area restructured power system. The changes in area loads and abnormal conditions arising from faults result to deviation in frequency and scheduled power interchanges.

Various control strategies in Load Frequency Control have been proposed by researchers in the past. A new economic dispatch model that deals with scheduling of generating stations when load demand occurs was proposed by [5]. At present, human operators at the load dispatch centers carries out the load scheduling with the help of Supervisory Control and Data Acquisition (SCADA). The conventional controls for LFC based on optimal control have been proposed by $[6,7]$. These conventional controls become impotent when the size and parameters of the power system increases.

The draw backs of the conventional methods led to the applications of Artificial intelligence control. Both the steady state error and settling time are lowered by the use of fuzzy logic as proposed by [4, 9, and 10]. Fuzzy logic is an approach to computing based on degrees of truth rather than the usual Boolean logic "true or false". The choice of correct membership functions and rule base determines the effectiveness of the fuzzy control. In this paper, a $7 \times 7$ rule base fuzzy logic control is applied to one-, two-and threearea power system. All simulation results which are based on MATLAB soft coding shows improvement over the conventional control in every aspect. The rest of the paper is organized as follows; section two presents the mathematical model of an interconnected power system, section three presents the proposed fuzzy logic controller while the simulation results are presented in section 4. Finally, in section five the conclusion was drawn.

\section{POWER SYSTEM MODELLING}

The modern power systems are divided into areas. These various areas are connected together through tie-lines. In which case, the tie-lines are utilized for contractual energy exchange between areas and provide inter-area support in abnormal conditions. The trend of frequency measured in each control area is an indicator of the trend of the mismatch power in the interconnection and not in the control area alone. A power system with $\mathrm{N}$-control areas as shown in Fig. 1 is made up of single area power systems as in Fig. 2.

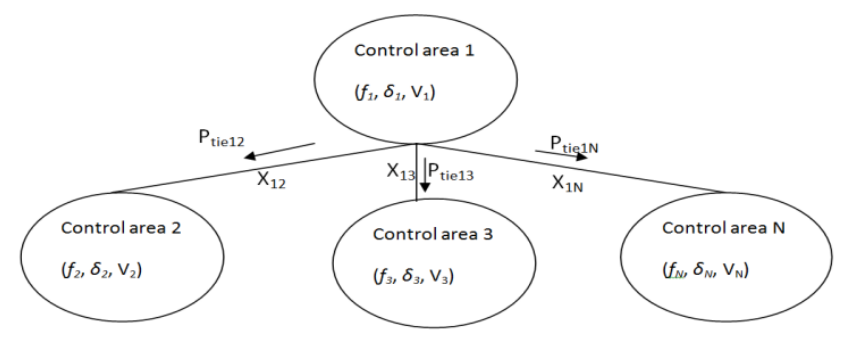

Fig. 1: $N$-controlled areas power system

\subsection{Single Area System}

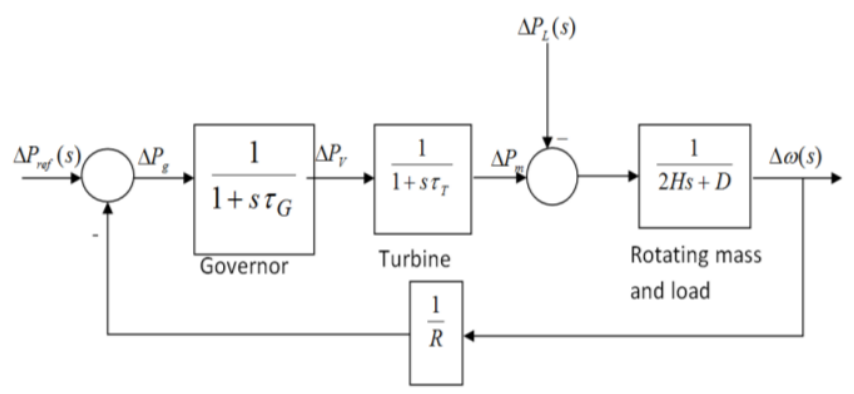

Fig. 2: Single area power system

In Fig. 2, $\Delta \mathrm{P}_{\text {ref }}(\mathrm{s})$ is the Reference power, $\Delta \mathrm{P}_{\mathrm{D}}(\mathrm{s})$ is the Load change, $\tau_{G}$ is the governor time constant, $\tau_{T}$ is the turbine time constant, $\mathrm{R}$ is the self regulation of generator, $\mathrm{H}$ is the Inertia constant, $\mathrm{D}$ is the Load frequency constant, and $\Delta \omega$ is the Change in rotational speed

The dynamic response of a single area power system under controlled case is given by the transfer function:

$$
\frac{\Delta \omega(s)}{-\Delta P_{D}(s)}=\frac{s\left(1+\tau_{G}\right) s\left(1+\tau_{T}\right)}{s(2 H s+D)\left(1+\tau_{G}\right)\left(1+\tau_{T}\right)+K_{I}+\frac{S}{R}}
$$




\subsection{Two Area Power Systems}

A two area power system consists of interconnection of two sets of single area systems, through tie-lines as shown in Fig. 3.

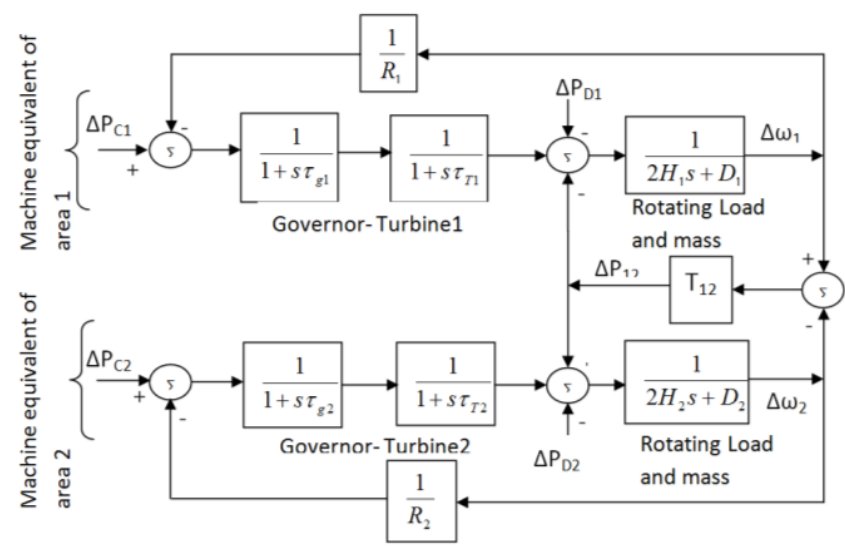

Fig. 3: Two-area system without control for a non-reheat turbine

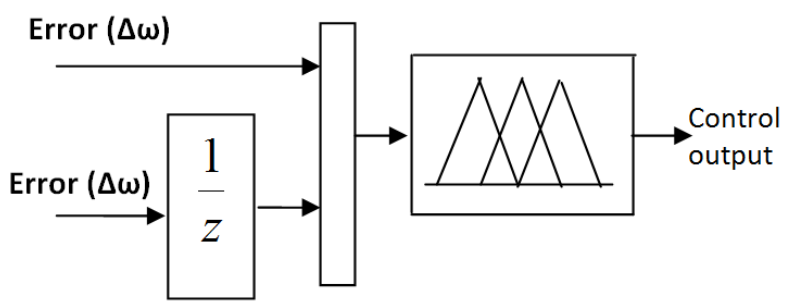

Fig. 4: Fuzzy Controller Installed on $i^{\text {th }}$ Area

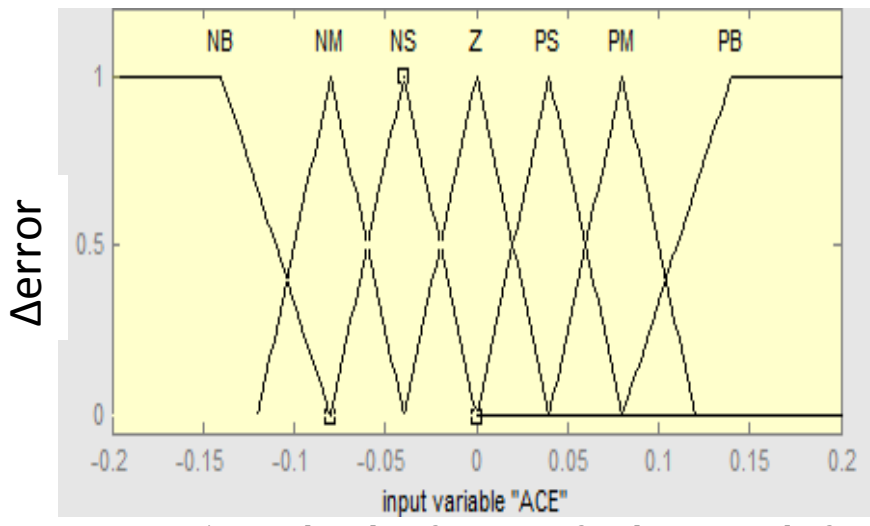

Figure 5: Membership functions for the integral of error

Table 1: Decision table for 7 X 7 rules for the Fuzzy - LFC

\begin{tabular}{|c|c|c|c|c|c|c|c|}
\hline \multicolumn{8}{|c|}{ Error } \\
\hline U & NB & $\mathrm{NM}$ & NS & ZE & PS & $\mathrm{PM}$ & PB \\
\hline $\mathrm{NB}$ & PB & PB & PB & PB & PM & PM & ZE \\
\hline NM & PB & PM & PM & PM & PS & ZE & PS \\
\hline NS & PM & PM & PS & PS & ZE & PS & ZE \\
\hline ZE & NS & NS & NS & ZE & PS & PS & PS \\
\hline PS & $\mathrm{ZE}$ & NS & ZE & NS & NS & $\overline{N M}$ & $\overline{N M}$ \\
\hline$\overline{\mathrm{PM}}$ & NS & ZE & $\mathrm{NM}$ & $\mathrm{NM}$ & $\mathrm{NM}$ & $\mathrm{NB}$ & NB \\
\hline$\overline{P B}$ & ZE & $\overline{N M}$ & NB & $\mathrm{NB}$ & NB & NB & NB \\
\hline
\end{tabular}

The information about the local area is found in the tie line power fluctuations. Consider a two area power system represented by an equivalent generating unit interconnected by a lossless tie-line with reactance, $\mathrm{X}_{\text {tie. }}$ During normal operation, the real power transferred over the tie-line is given by

$$
P_{12}=\frac{/ E_{1} / / E_{2} /}{X_{12}} \operatorname{Sin} \delta_{12}
$$

Where, $\mathrm{X}_{12}=\mathrm{X}_{1}+\mathrm{X}_{\text {tie }}+\mathrm{X}_{2}$, and $\delta_{12}=\delta_{1}-\delta_{2}$. And the tieline power $\Delta \mathrm{P}_{12}=\mathrm{P}_{\mathrm{s}}\left(\Delta \delta_{1}-\Delta \delta_{2}\right)$. If $\Delta \delta_{1}>\Delta \delta_{2}$, then power flows from area 1 to area2.

A supplementary control introduced to a two area power system known as the tie line bias control keeps the frequency approximately at the nominal value, maintain the tie line flow at the scheduled value and allows each area to absorb its own load changes first. The control of a conventional PI Load Frequency Control is based on tie-line bias, with each area tending to reduce each area control error (ACE) to zero [4]. The ACE of each is given by

$$
A C E_{i}=\sum_{j=i}^{n} \Delta P_{i j}+K_{i} \Delta \omega
$$

Where $\mathrm{K}_{i}$ is chosen such that $K_{i}=B_{i}=\frac{1}{R_{i}}+D_{i}$ for satisfactory operation. So for two area systems,

$$
\begin{aligned}
& A C E_{1}=\Delta P_{12}+B_{1} \Delta \omega_{1} \\
& A C E_{2}=\Delta P_{21}+B_{2} \Delta \omega_{2}
\end{aligned}
$$

From equation (2), the non-linearity in power flow equation makes it difficult for conventional control to handle, hence the need for alternative control mechanism that does not require mathematical model of the system.

\section{FUZZY LOGIC CONTROLLER DESIGN}

In power systems, because of the inherent characteristics of the changing loads and the system non-linearities such as generation rate constraint, there is no analytical method to determine optimal parameters quickly for real time application [11]. Artificial Intelligence systems have the capacity to deal with this non-linearities and parameter changes. Fuzzy logic control works on rule base formulated from the experiences of the plant operators. It takes care of system non-linearities and performance outside the operating region [4]. Fuzzy Logic Controller design is a three-stage process which comprises fuzzification module, Rule base and Defuzzification module. A fuzzy logic controller for LFC using frequency deviation and rate as inputs was proposed by [12]. In this paper, the Area Control Error (ACE) is the fuzzy inputs as shown in Fig. 4. The

Vol. 35. No. 3 July 2016 
linguistic variables used here are Positive Large (PL), Positive Medium (PM), Zero (Z), Negative Small (NS) etc. and has a membership value as shown in Fig. 5 . The $7 \times 7$ rule base in the inference mechanism is shown in Table 1.

\section{SIMULATION RESULTS}

The fuzzy logic controller has been applied to a single and multi-area power system with the following parameters;

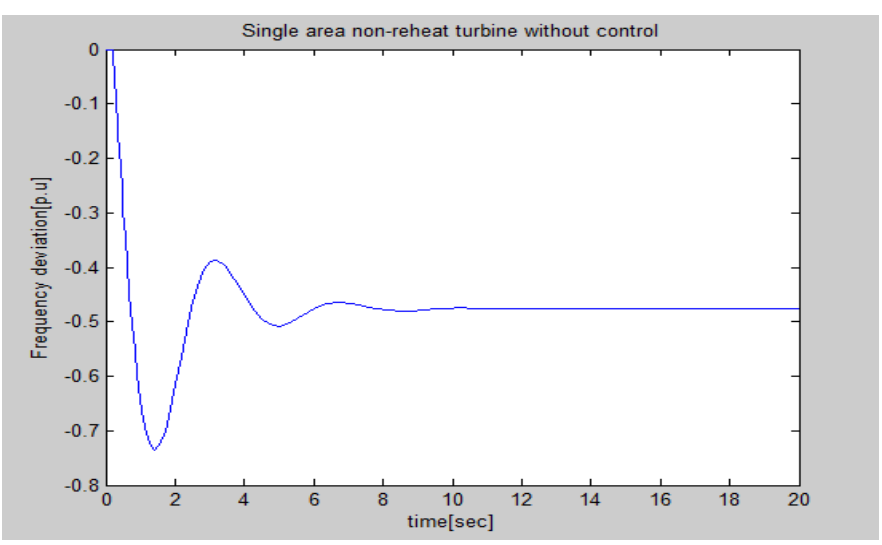

Fig. 6: Frequency step response for a single area without control

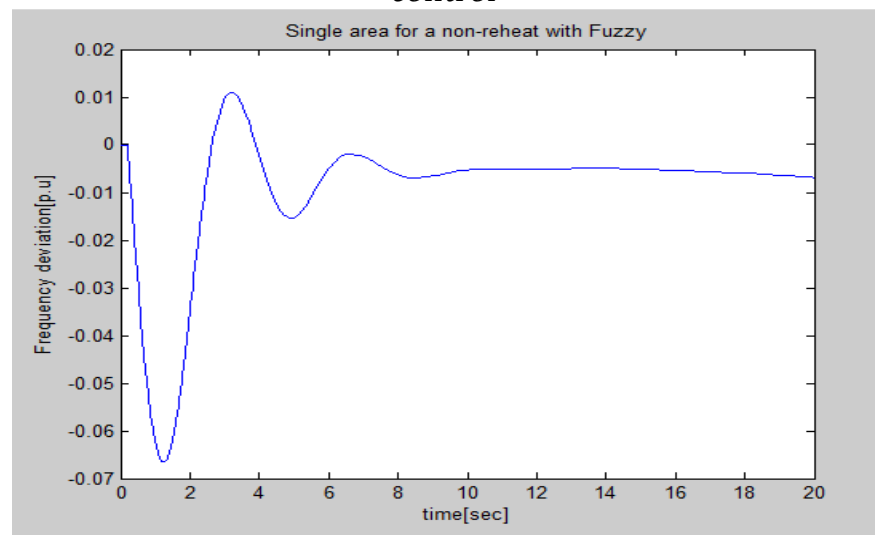

Fig. 8: Frequency step response for a single area with Fuzzy control

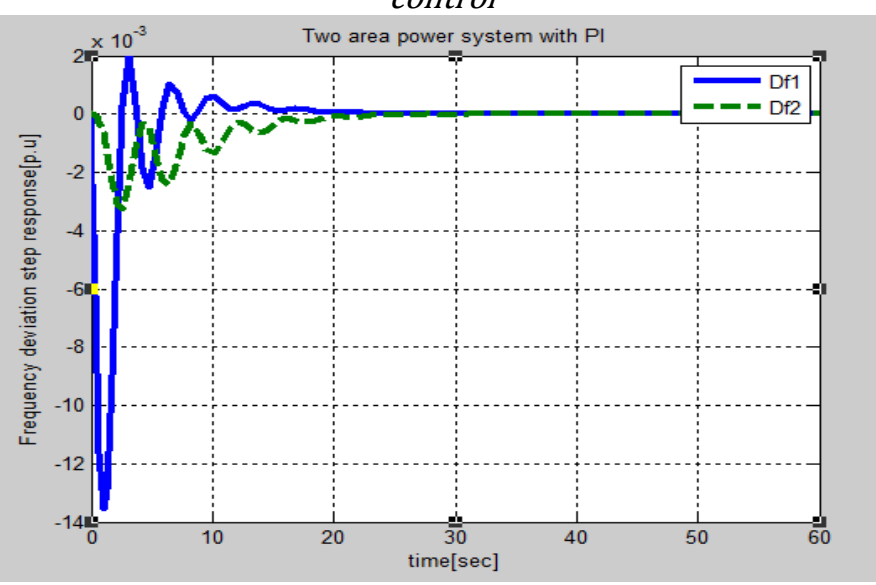

Fig. 10: Frequency deviation step response for a two areas with PI control
$\mathrm{T}_{\mathrm{g}}=0.08 \mathrm{sec}, \mathrm{T}_{\mathrm{t}}=0.3 \mathrm{sec}, \mathrm{H}=0.167, \mathrm{D}=0.00833, \mathrm{~B}$ $=0.6$ and $\mathrm{R}=1.66$. The simulation was carried out in MATLAB environment. The performance of the fuzzy controller was compared with a conventional controller and the simulation results are presented in Fig. 6 through 8. A step load of 0.02 p.u was applied to each area.

As seen from Fig. 7 and 8, the steady state response is reached faster with the application of fuzzy. The overshoot was also reduced from 0.05 to 0.01 .

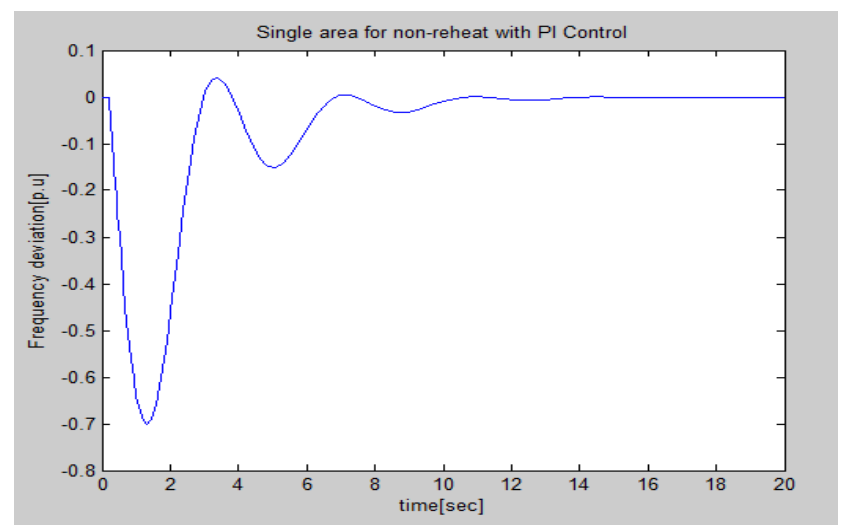

Fig. 7: Frequency step response for a single area with PI control

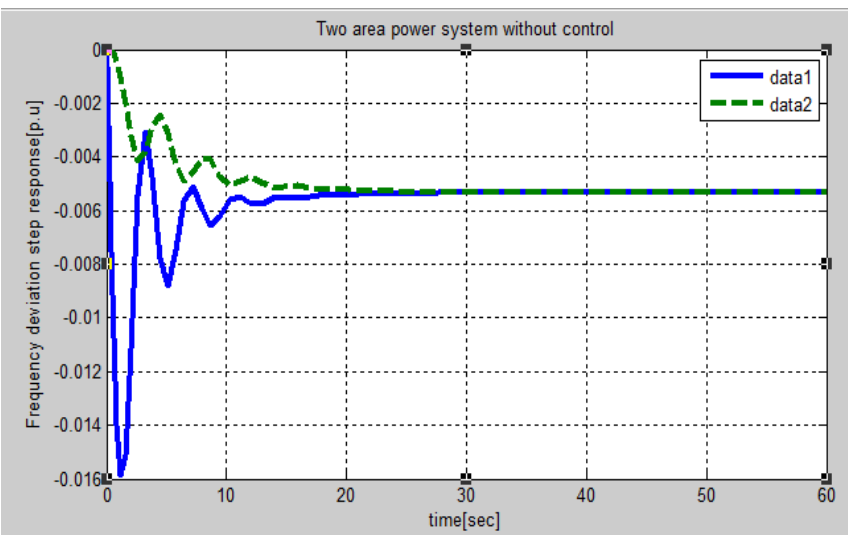

Fig. 9: Frequency deviation step response for two areas without control

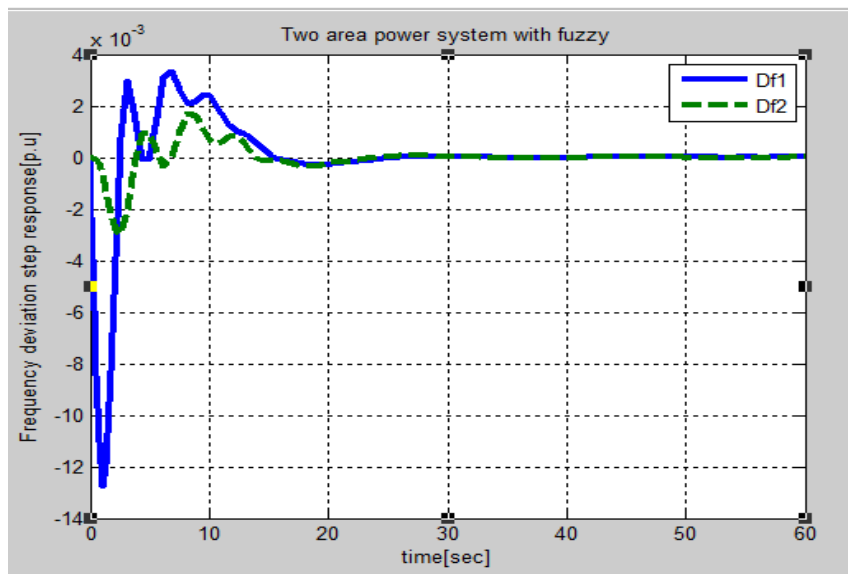

Fig. 11: Frequency deviation step response for a two areas with Fizzy control 
The response obtained from fuzzy in Fig. 11 settles faster at approximately 16 seconds than with PI control. The performance of the system can also be improved by increasing the number of the membership functions. Under different parameter variations, there is also an edge fuzzy has over conventional control as shown in Figures 12 and 13.

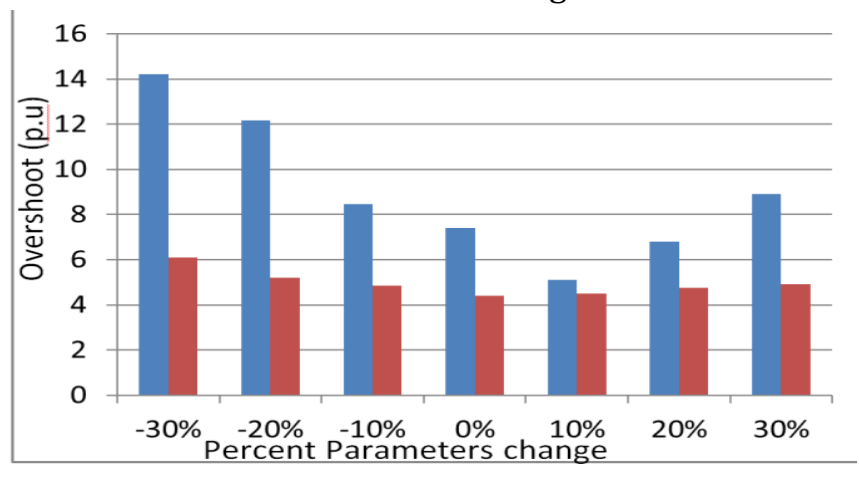

Fig. 12: Overshoots under parameter variations.

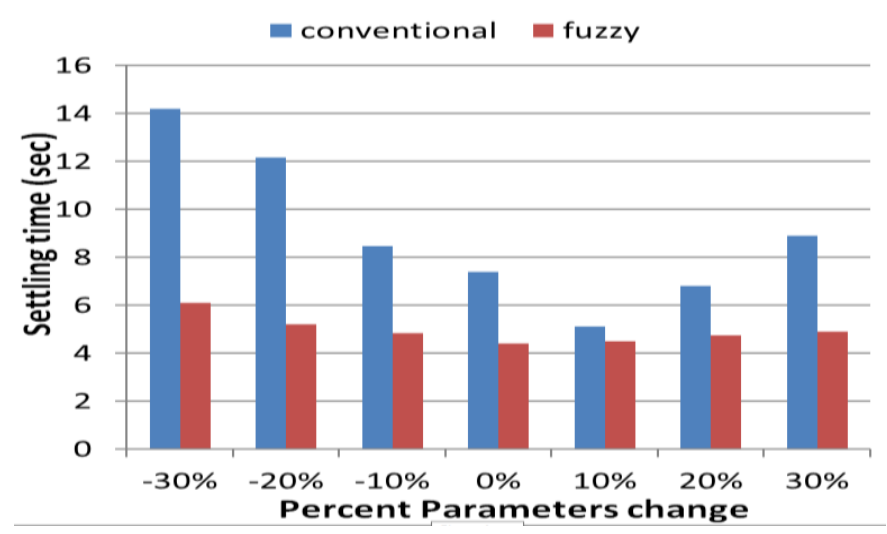

Fig. 13: Settling time under parameter variations.

\section{CONCLUSION}

In an interconnected power system, LFC is very important in keeping frequency deviation to a minimum. The conventional control has large settling time, overshoot and oscillations. These are due to nonlinearity. The fuzzy logic control was able to improve the performance of the controller even in the presence of non-linearity. The overshoot was reduced by $30 \%$ when fuzzy was applied and also the system settled at a lower time. The application of Artificial Intelligence is recommended in tackling frequency instability of a power system. The non-linearity is overcome since the mathematical model of the system is not an issue with Artificial Intelligence.

\section{REFERENCES}

[1] Y. Hssu and W. Chan, 'Optimal Variable Structure Control of Interconnected Hydrothermal Power Systems', Electrical Power and Energy Systems, 1984, pp 22-31.

[2] S. O. Okozi, S. N. Ndubisi and T. C. Madueme, 'A fuzzy logic based Automatic voltage Regulator for alternator terminal voltage and reactive power control', International Journal of Electrical and Electronic Engineering, vol. 1, No. 2, 2009, pp 63-71.

[3] O. I Elgerd and C. E. Fosha Jr, 'Optimum MegawattFrequency Control of Multiarea Electric Energy Systems', vol. PAS-89, No.4, April 1970, pp 556-562.

[4] S. Pothiya, I. Ngamroo, S. Runggeratigul and P. Tantaswadi, 'Design of Optimal Fuzzy Logic based PI Controller using Multiple Tabuu Search Algorithm for Load Frequency Control', International Journal of Control, Automation, and Systems, Vol. 4, no. 2, pp 155-164, April 2006.

[5] K. P. Singh, S. Majhi and D.P Kothari,' Optimal Load Frequency Control of an Interconnected Power system', MIT International Journal of Electrical and Instrumentation Engineering vol. 1, No. 1, 2011, pp 1-5.

[6] Y. Hssu and W. Chan, 'Optimal Variable Structure Control of Interconnected Hydrothermal Power Systems', Electrical Power and Energy Systems, 1984, pp 22-31.

[7] A. E. Milani, B. Mozafari, 'Genetic Algorithm Based Optimal Load Frequency Control in two area interconnected power systems', Global journal of technology and optimization, vol. 2011, pp 6-10.

[8] T. Hiyama, S. Konga and Y. Yoshimuta, 'Fuzzy Logic Based Multi-Functional Load Frequency Control', IEEE Power Engineering Society 2000, vol. 2 pp 921926.

[9] P. Kundur, 'Power systems stability and control', New York, NY, McGraw-Hill companies Inc. 1994.

[10] P.V.R. Prasad and M. S. Veeraju, 'Fuzzy Logic Based Analysis of Load Frequency Control of Two Area Interconnected Power System', International Journal of Emerging Technology and Advanced Engineering, vol. 2, issue 7, July 2012, pp321-327

[11] S. Haadi, 'Power systems Analysis' McGraw-Hill companies Inc. 1999.

[12] A. Soundarrajan et al, 'Intelligent controllers for Automatic Generation Control', Proceedings of the International conference on Robotics, vision, Information and signal Processing, Malaysia, 2003, pp. 307-311. 